\title{
The World Congress of Gastroenterology: Montreal, Quebec, September 12-14, 2005
}

\author{
Dilip G Patel MD FRCPC \\ Treasurer, World Congress of Gastroenterology
}

\begin{abstract}
The World Gastroenterology Organization, or OMGE, is a 1 federation of 93 national societies and associations of gastroenterology representing over 50,000 members worldwide. One of its major missions is to organize and present a World Congress of Gastroenterology (WCOG) every four years. Member societies, just as with Olympic committee members, vote after a formal bidding process and the winner hosts the next meeting. We have received that honour and privilege of hosting the WCOG in Montreal in September 2005. With privilege comes responsibilities, and that goes for every man and woman who cares for the future of gastroenterology in Canada.
\end{abstract}

\section{WHOSE MEETING IS THIS?}

It is not the meeting of the Canadian Association of Gastroenterologists, the Canadian Association for the Study of the Liver or the Canadian Organizing Committee (COC). It is our meeting and our chance to show the world our talent, achievements and generosity. To paraphrase a famous statesman, John Kennedy, ask not what the Canadian Association of Gastroenterologists or the COC can do for you, but ask what you can do for your love of gastroenterology. The least we can do is to attend the meeting. A varied program will satisfy different needs. Whether you are a luminologist, hepatologist, endoscopist, nutritionist or simply a party-goer, you will not be disappointed.

\section{FINANCES}

The COC receives funds from OMGE based on a predefined budget and categories of expenditures. It is received on submission of standard expense claims in the amount of $\$ 50,000$, and the total budget is approximately US $\$ 420,000$ to organize this meeting. There are many people working long voluntary hours to make this meeting a success. When one works hard at something, success is expected. Moreover, we are also interested in monetary gain because $20 \%$ of the profit comes to Canadian gastroenterology.

\section{PITCH}

In economic terms, the world is divided into developed, developing and underdeveloped. Notwithstanding those differences, the registration fee for the WCOG is the same for all, and one can argue that it is not fair. The Asian and African countries raise this concern. The OMGE will have to address that. We are not in that boat. The rest of the world envies Canadians, because we are rich, caring and socially conscious people. When I hear that the registration fee is high and we should ask for a discount, etc, I get the most refractory heartburn of my life. Even the mother of proton pump inhibitors cannot relieve this heartburn. Register before January 1, 2005 and it is US\$520. It goes up afterwards. I, for one, am not prepared to believe that on this rare occasion we cannot stand up and afford to pay the registration fee. The world is coming to Canada and I don't want to tell you how you can put aside $\$ 520$, but let me be bold and suggest:

1. Reduce to drink a few bottles of wine a month;

2. Cut out one outing a month; or

3. Take a little bank from your child or grandchild and put one endoscopy fee in once a month for a few months and you are assured to have the registration fee.

Moreover, don't forget your registration cost is reduced by one-half because it is tax deductible.

\section{PAST}

I have heard that some meetings in the past had problems. I really don't know what that has to do with the WCOG. Let me reflect by stating that the past is history and it is only good to learn lessons for the future. Dwelling on the past will lead us to a downward path. Let us look at the future and it is ours but only if we care. The world is watching us and deservingly expecting a great meeting.

\section{COLLEAGUES IN QUEBEC}

Mes ami(e)s. The world is coming to what better place than the French Canadian culture in the heart of Montreal. Whatever your views, don't forget this is our meeting. It is our cultural diversity that makes us unique in the world scene and this is a global show requiring a global presence. Please register in large numbers.

\section{CONCLUSION}

Join one by one. Don't wait for gifts. We have received enough, and for the future of gastroenterology and a legacy for our bright young Canadians, let us work for resounding success. Trust me, profit will be managed for gastroenterology with transparency and honesty.

Register, register, register. The sooner the better, and cheaper. If not, I will be knocking on your door.

Division of Gastroenterology, The Ottawa Hospital, Ottawa, Ontario

Correspondence and reprints: Dr Dilip G Patel, Chief, Division of Gastroenterology, The Ottawa Hospital, Civic Campus, A1, Gastroenterology, 1053 Carling Avenue, Ottawa, Ontario K1Y 4E9. Telephone 613-761-4501, fax 613-761-4147, e-mail dpatel@ottawahospital.on.ca 


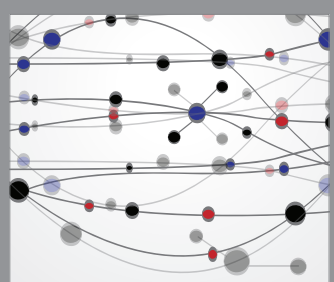

The Scientific World Journal
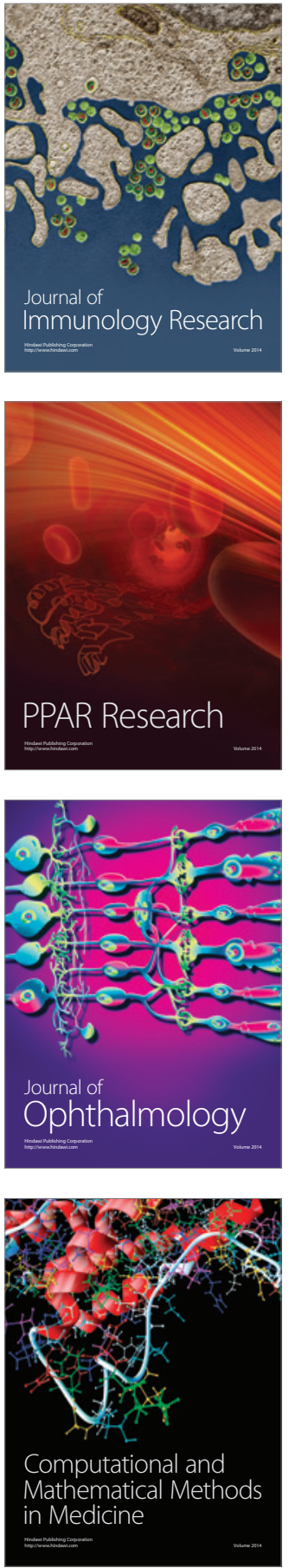

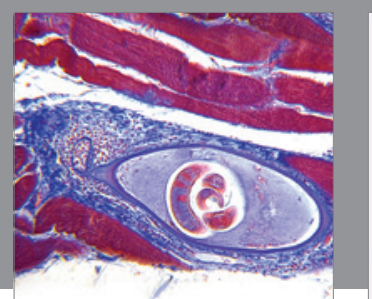

Gastroenterology Research and Practice

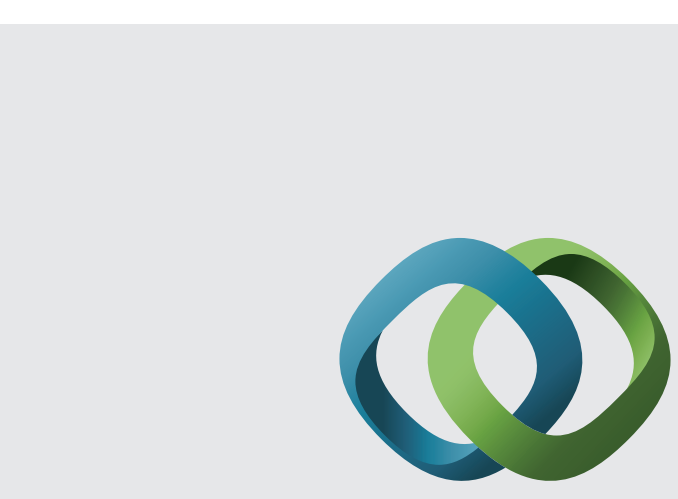

\section{Hindawi}

Submit your manuscripts at

http://www.hindawi.com
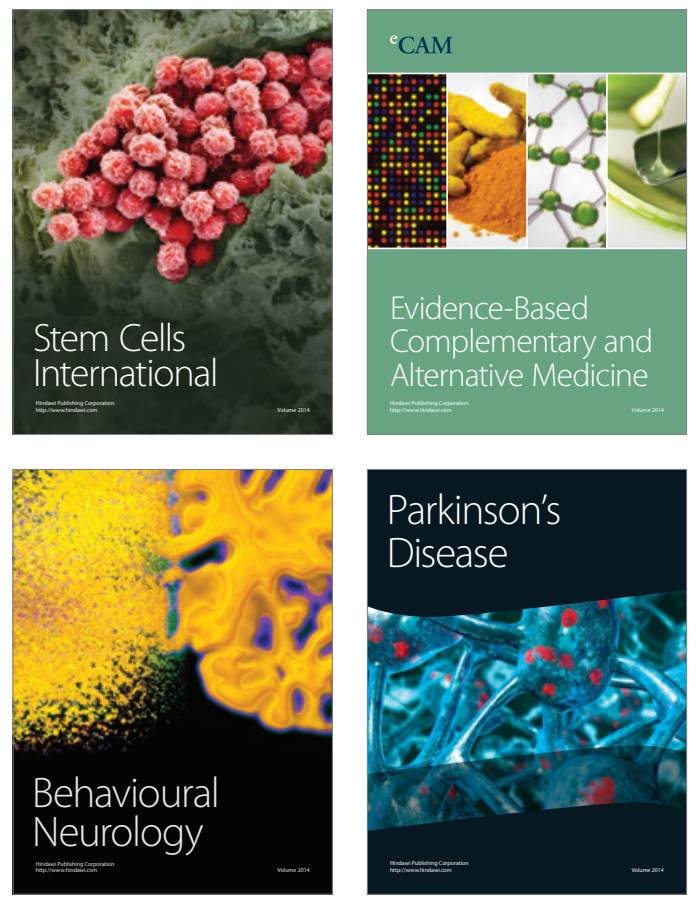
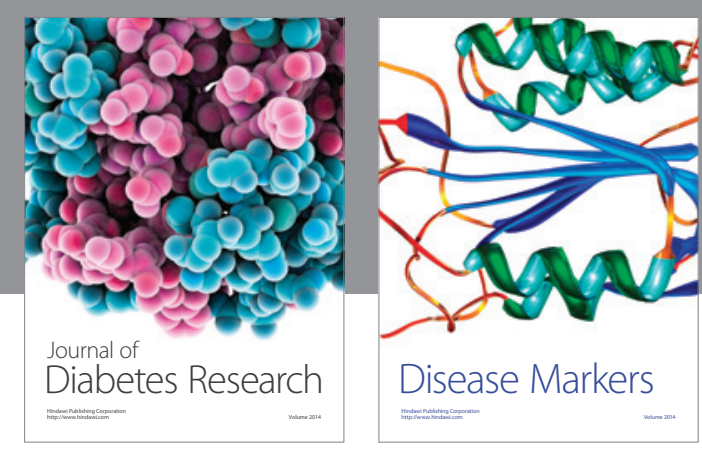

Disease Markers
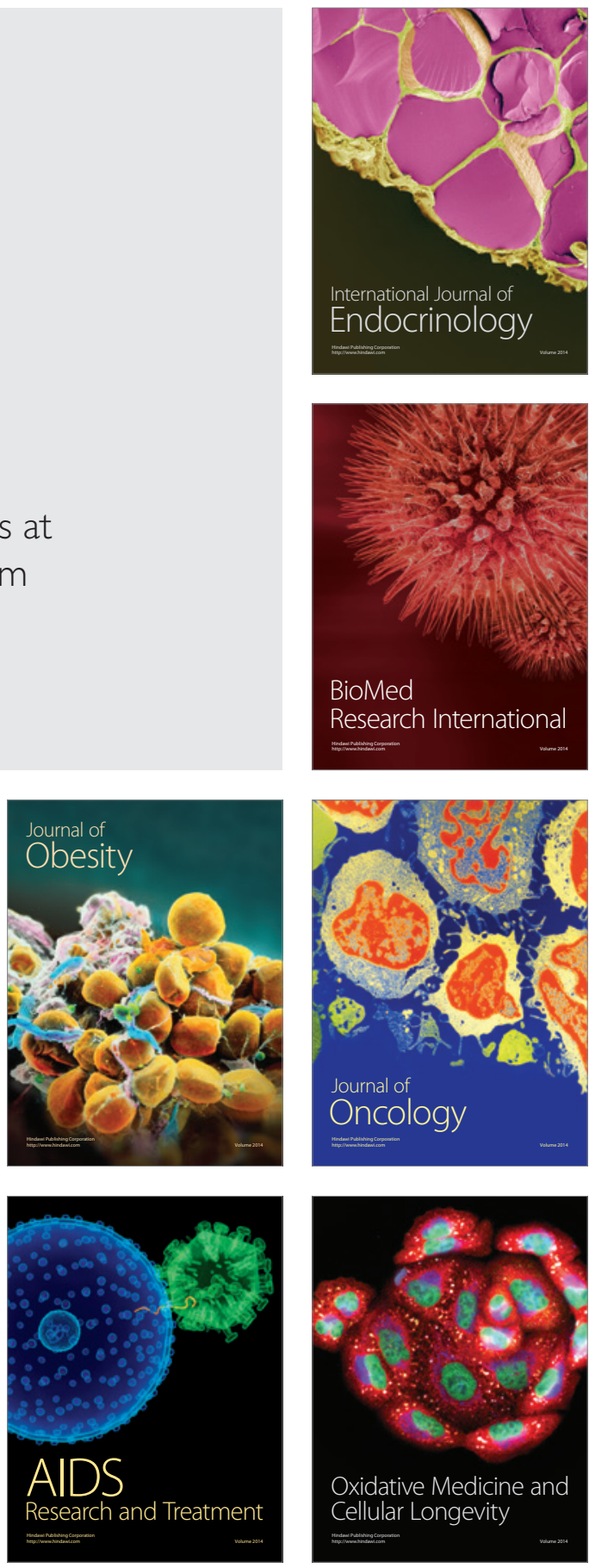